\title{
Reconstruction of Walleye Exploitation Based on Angler Diary Records and a Model of Predicted Catches
}

\author{
This is a postprint of the article published in Mathematical Biosciences 210 (1) (2007) 96-120. \\ Allan R. Willms* \\ Department of Mathematics and Statistics, \\ University of Guelph, \\ Guelph, ON N1G 2W1, Canada \\ AWillms@uoguelph.ca \\ phone: 519-824-4120 x52736 \\ fax: 519-837-0221 \\ David M. Green ${ }^{\dagger}$ \\ NY State College of Agriculture and Life Sciences, \\ Cornell University, \\ Ithaca, NY 14853, USA \\ dmg5@cornell.edu
}

Sept. 2007

* Corresponding author.

${ }^{\dagger}$ Now retired. 


\begin{abstract}
The walleye population in Canadarago Lake, New York, was 81-95\% exploited in the 1988 fishing season, the year in which a previous restriction on the length and number of legally harvestable fish was liberalized. Using diary records from a subset of fishermen, growth estimates, and an estimate of the walleye population in the following year, a method is developed to reconstruct the fish population back to the spring of 1988 and thus determine the exploitation rate. The method is based on a model of diary catches that partitions time and fish length into a set of cells and relates predicted catches and population sizes in these cells. The method's sensitivity to the partitioning scheme, the growth estimates, and the diary data is analyzed. The method could be employed in other fish exploitation analyses and demonstrates the use of inexpensive angler-collected data in fisheries management.
\end{abstract}

Keywords: walleye; exploitation rate; angler diary records; size-structured model 


\section{Introduction}

Canadarago Lake is an 809 ha lake located in east-central New York and has been the subject of study by the New York State Department of Environmental Conservation (DEC) and Cornell University for many years. Some of these studies and background information to this study are given in the following section.

Extensive sampling from 1973-76 showed that the fish population consisted of a low density population of predators (gamefish) and an abundant population of several slow growing, small size panfish and forage fish [1]. In an attempt to improve the recreational fishery of Canadarago Lake, stocking of walleye fingerlings (Sander vitreus) from 1977-82 was carried out and, unlike previous stocking attempts, was successful [2]. To allow a population of mature walleye to develop and reproduce, a special fishery regulation for Canadarago Lake was imposed on walleye in spring 1977 reducing the daily creel limit from 5 to 3 fish and increasing the minimum harvest size from $381 \mathrm{~mm}$ (15 inches) to $457 \mathrm{~mm}$ (18 inches). During the planning stages of the first investigation (1973-76) and subsequent stocking experiment to modify the fish population structure, follow up evaluations had been planned including a one year repeat of the procedures used during the first investigation. This follow up study was to be combined with a creel survey to evaluate the resulting fishery and determine exploitation rates following the predator stocking program. Major changes in the fish population occurred more rapidly than anticipated. It was apparent in late 1986 that liberalization of the fishing regulations needed to be made to prevent density dependent growth of walleye and possibly other predator species. It was too late in the year to make the regulation changes effective for May 1987 and instead, the walleye regulations reverted back to the statewide regulations (daily limit of 5 fish, minimum length 15 inches) in May 1988. However, in spite of prior planning, bureaucratic circumstances did not synchronize with the requirements of science and funding for the evaluation studies did not occur until the 1989-91 period.

To fill the gap in information, the DEC initiated an angler diary program to collect information on the fishery during 1988 and 1989 [3]. The diary program would provide catch information during 1988, the first year the regulation change occurred, and during 1989 concurrent with a creel survey and fish population study. Total catch, numbers of walleye harvested, and major changes in the size of fish caught by diary program anglers and changes in population size structure during the 1989 study suggested that harvest of walleye had been very high. Because of the evidence that exploitation might have been excessively high, there was interest in documenting the extent of the exploitation.

The senior author was approached to develop a method using the diary records, to estimate the exploitation of walleye in 1988. The method is based on a model of predicted catches for the diary anglers. Fish size is partitioned into several length classes, and time, into a number of intervals based on diary fishing hours. The primary assumptions are that for any given time interval and two adjacent length classes, (i) the ratio of fish caught by the diary anglers in the two classes is equal to the ratio of total fish in those two classes, and (ii) the ratio of the total number of fish harvested from the two classes is equal to the ratio of the catches. Some justification for these assumptions is provided below. Although walleye growth was minimal in the lake in 1988, for wider applicability, the model incorporates fish growth, in this case through water temperature, zooplankton size, and fish scale data. The model walleye populations in each length class and the predicted diary catches are fit by minimizing the least squares error between the predicted catches and the recorded diary catches. Mathematically this is a nonlinear optimization problem with both linear and nonlinear equality and inequality constraints. 


\section{Background and Methods}

\subsection{Background}

The following information is provided to give the background to the major changes that occurred in the fish population and fishery of Canadarago Lake following the successful introduction of walleye beginning in 1977.

Water chemistry, aquatic plants, zooplankton, benthos, fish $[1,4,5,6]$ and fisheries management $[2,7,8]$ of Canadarago Lake was studied extensively between 1968 and 1981. Less intensive sampling continued through 1986 and the sampling schedule conducted from 1973 to 1976 was repeated again in 1989 [3, 9, 10].

During the 1973-76 period the fish population consisted primarily of a low density (mean, $3.7 \mathrm{~kg} / \mathrm{ha}$, $\geq$ age $1+$ ) predator (gamefish) population of smallmouth bass (Micropterus dolomieui), chain pickerel (Esox niger), and largemouth bass (M. salmoides), and an abundant population of several slow growing, small sized panfish and forage fish. Density of yellow perch (Perca flavescens), the most abundant panfish present, ranged from $739 /$ ha-1845/ha, $\geq 127 \mathrm{~mm}$, and only $4-13 \%$ of the perch exceeded $202 \mathrm{~mm}$ [1]. A detailed survey in 1935 and more cursory surveys in 1954 and 1958 by the New York fisheries agency (now the DEC) showed the predator and the panfish abundance and composition were similar to that in the early 1970s [11, 12, 13].

Abundant, slow growing panfish and low density predator fish populations are common and, in general, provide, at best, a mediocre recreational fishery. Because of the fish population structure and the existing fish population database, Canadarago Lake was selected to evaluate a fishery management program, based on stocking fingerling walleyes (Sander vitreus), that had the objectives of increasing the numbers of predators, decreasing the numbers of panfish and increasing the growth rate of panfish. These same objectives had been pursued by the state fishery agency since the 1920s through the stocking of predator fish fry and adults and these various stockings, including the stocking of walleye fry for several decades, all failed to alter the fish population structure [1].

Walleye fingerlings, mean length $74-102 \mathrm{~mm}$ at densities of 4.6/ha-19.4/ha were stocked from fall 1977 through 1982 [2]. Mean survival of stocked walleye fingerlings over the first year to 1.5 years was $17 \%$ for the four years that fall fingerlings averaged $\geq 88 \mathrm{~mm}$ when stocked. Survival was $<1 \%$ for the two years fall fingerlings were $<84 \mathrm{~mm}[2]$. The first year mature walleye of both sexes were present as a result of the stockings was 1981 and in falls of 1981-83 cohorts of 300 or less fingerling walleye were produced. The walleye biomass resulting directly from the stocking program reached $4.5 \mathrm{~kg} / \mathrm{ha}$ fish by 1983 , more than doubling the total predator biomass $[2,8]$. Strong walleye cohorts hatched in 1984-86 (23.4/ha, 12.8/ha, and 14.5/ha, age 1+ respectively) and predator biomass increased further.

Information recorded in the diaries of anglers participating in the DEC program indicated large numbers of walleye were harvested in 1988. The anglers keeping diaries represented only a small proportion of the total number of anglers fishing in Canadarago Lake. From May to July of 1988 these cooperating diary anglers caught large numbers of walleye, especially in the previously protected 381-457 mm (15-18 inch) range: 890 legal length walleye were caught in 3,342 fishing hours. Nondiary anglers would have caught and harvested many more fish. Catch per hour of walleye by diary cooperators was very high. Diary cooperators targeting walleye caught 0.95 walleye/hour of all sizes and 0.29 legal length walleye/hour, harvesting $75 \%$ of the legal length walleye they caught [3]. Colby et al. [14] reviewed North American walleye fisheries and reported that catch of anglers fishing specifically for walleye showed a mode of 0.11-0.15 walleye per hour range but 17 of the 18 estimates were below 0.35 . Declining length of walleye in the cooperator catch of all walleye, including fish released, 
suggested that exploitation was high. Average length of walleye in the cooperator catch was $391 \mathrm{~mm}$ in May 1988, mean length declined almost $18 \mathrm{~mm}$ a month through September 1988, and was only $290 \mathrm{~mm}$ by May 1989 [3].

By the next year, the fishery had changed dramatically. Diary cooperator walleye catch rates of harvestable size declined four-fold from 1988 to 1989 and the number of walleyes harvested by diary cooperators in 1989 was only $22 \%$ of the number harvested in 1988. Between May 6, 1989 to March 15, 1990 the creel survey indicated that all anglers caught more than 15,000 walleye, however, because few walleye were greater than $381 \mathrm{~mm}$ (minimum legal length) only 307 were harvested [3].

\subsection{Methods}

Anglers who had participated in a diary program during a study of bass populations in Canadarago Lake from 1976-80 [7], some of whom continued to maintain diaries after 1980, were requested to participate in the May 1988 to March 1990 diary program. These anglers had all attended sessions for instruction on keeping their diaries, measuring fish, and were provided with a measuring board. In addition they received semi-annual updates on the program and common errors were discussed. In an evaluation of the accuracy of measurements by those keeping diaries in the bass study, 93 tagged bass measured by anglers and biologists within a maximum of 20 days of each other found that the average difference in length was only $2.5 \mathrm{~mm}$ longer for fish measured by the cooperators. Mean lapsed time between bass measured by biologists and cooperating anglers was 10.7 days [7].

Additional anglers were recruited to keep diaries during the 1988-91 period. Some of these recruited anglers attended meetings where procedures were demonstrated and all received written instructions on completing daily fishing trip information. All anglers were instructed to record the following: date and beginning and ending time of each trip, the species of fish for which they were fishing on a particular trip, the method of fishing (boat or shore) and to list each fish caught, length of the fish and whether they creeled (kept) or released the fish. Diaries were collected from anglers at the end of each year. Forty-one anglers maintained diaries in 1988 and 29 in 1989.

Estimates of age two and older walleye were by the Petersen method [15] using mark (fin clip) and recapture. Walleyes were collected for marking from April to early June 1989 and recaptured primarily in fall 1989. A few walleye were also taken in gill nets during summer 1989. Serns' $[16,17]$ catch per unit of shoreline method was used to estimate numbers of fall fingerling and spring yearling walleye.

Fish scales were collected from walleye and total lengths (tip of caudal fin) recorded. Scales impressions were made on plastic and age was determined by examining scale markings using a microprojector.

In 1988 temperatures were recorded from surface to bottom monthly and vertical zooplankton samples were collected with a $153 \mathrm{~mm}$ mesh $0.5 \mathrm{~m}$ zooplankton net. Zooplankton were preserved in $5-10 \%$ formalin. Individual zooplankton were projected on to a microprojector screen and were identified to species [18] in three $1 \mathrm{~mL}$ aliquots from each sample. Immature zooplankton including neonates and copepodites were also counted in all samples. Zooplankters were measured from the anterior margin of the head to the base of either the tail spine of cladocerans or the caudal rami of copepods. Counts and lengths were recorded with electronic callipers interfaced with a computer.

The numerical model was optimally fit to the catch data by software written in MATLAB [19] utilizing MATLAB's optimization toolbox function "fmincon". In order to reduce the number of variables, most of the equality constraints (specified in Sec. 3.2.3) were analytically imposed on the model before applying the optimization software. For each discretization scheme or set of parameter 


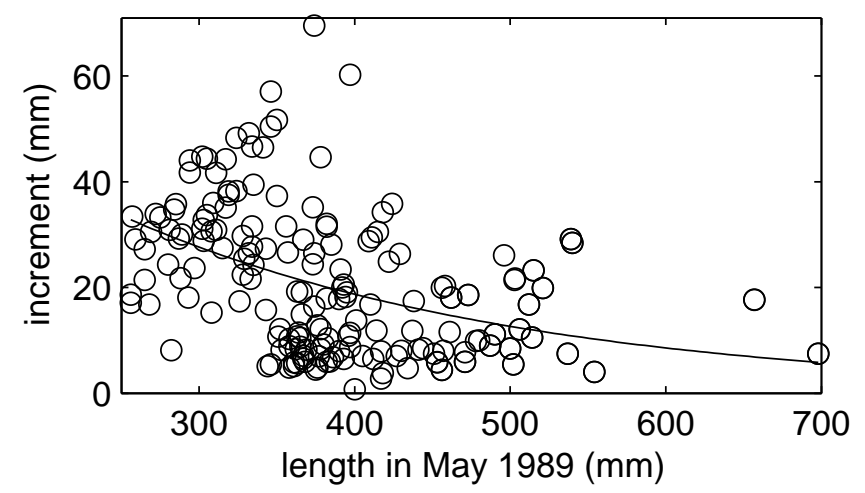

Figure 1: Incremental annual growth for walleye in 1988. Solid line is the best fit exponential function.

values, the optimization was run with six different sets of initial conditions and the run that converged to the lowest minimum was selected.

\section{Preliminary Results and Model Specification}

\subsection{Growth Parameters}

The growth over 1988 for the sampled fish is shown in Fig. 1 as a function of their length in May of 1989. A single exponential function was fit to these data giving a yearly growth function (in mm)

$$
\bar{g}(x)=89.18 \exp (-0.003905 x) .
$$

This curve is shown on the figure. This function along with the daily fraction of annual growth, described next, was used in the model to determine the length class boundaries through time.

Walleye growth in Canadarago Lake is determined mainly by water temperature and the availability of yellow perch, their primary prey species. Growth for walleye begins when the water temperature reaches about $12.8 \mathrm{C}$ [20], is approximately maximal when the temperature is about 21 or $22 \mathrm{C}$, and is minimal above about $27 \mathrm{C}[21,22]$. (Temperatures in Canadarago Lake did not exceed $25 \mathrm{C}$ in the study period.) Walleye feed primarily on yearling perch until about mid June when the young of the year perch reach about $18 \mathrm{~mm}$ [23]. When most of these young of the year perch have been consumed, usually around mid to late July, growth for walleye essentially stops. Given the species and size composition (large panfish/prey fish species) existing in the mid to late 1980's, an indicator for the number of (small) young of the year perch in the lake is the mean size of zooplankton [24, 8]. A small mean size, below about $0.8 \mathrm{~mm}$ [24], indicates a large number of young of the year perch since they selectively eat the large zooplankton. A large mean size indicates a small number of young of the year perch.

The water temperatures and zooplankton size in Canadarago Lake in 1988 and 1989 were used to distribute the annual growth of the walleye throughout the year. Recorded temperatures and mean zooplankton size are shown in Fig. 2A and 2B respectively. The growth distribution scheme assigned 


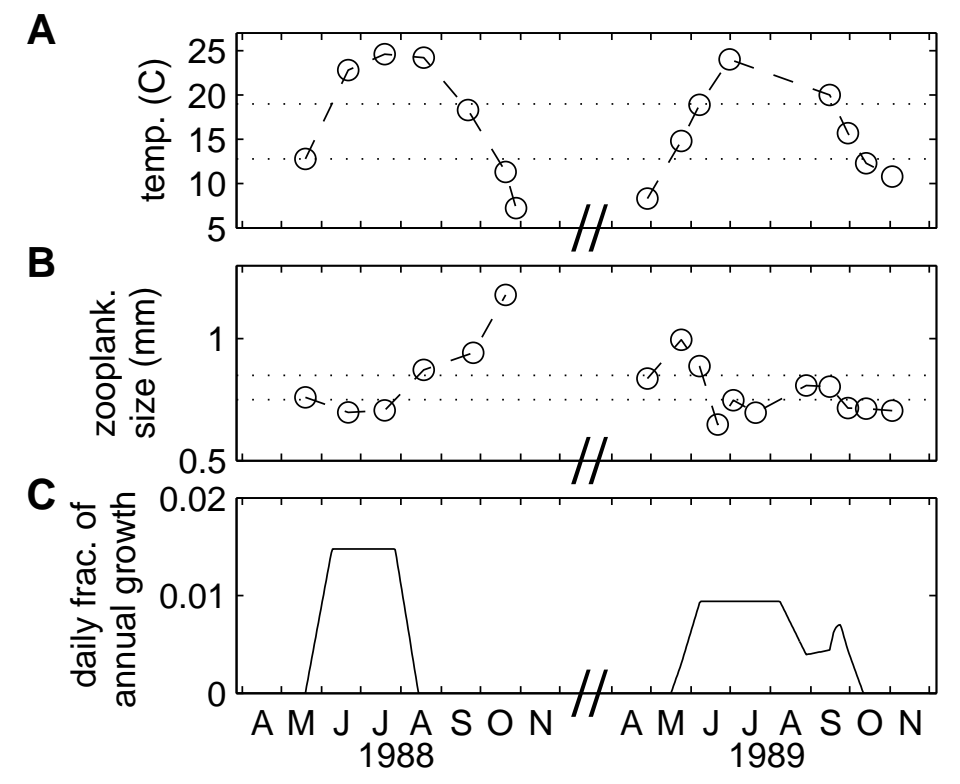

Figure 2: A. Water temperature in Canadarago Lake. Dotted lines are at $12.8 \mathrm{C}$ and $19 \mathrm{C}$. B. Zooplankton mean size; dotted lines are at 0.75 and $0.85 \mathrm{~mm}$. C. Daily fraction of annual growth; see text.

a maximal portion to days where the temperature is above $19 \mathrm{C}$ and the mean zooplankton size is below $0.75 \mathrm{~mm}$. A linearly increasing portion is given to the days in spring where the temperature is between $12.8 \mathrm{C}$ and $19 \mathrm{C}$, and a linearly decreasing portion is given to days in mid summer where the zooplankton size is between 0.75 and $0.85 \mathrm{~mm}$. The resulting daily fraction of the annual growth is shown in Fig. 2C. (Note that if growth occurred equally all year then the daily fraction would be $1 / 365 \approx 0.0027$.) The values $0.75 \mathrm{~mm}$ and $0.85 \mathrm{~mm}$ for zooplankton size are somewhat arbitrary, but the results are not very sensitive to these values (see below). Indeed, for relatively small growth situations, like this one, our method is rather insensitive to the growth and any reasonable estimate of the the growth parameters would be sufficient. The resulting growth period corresponds well with the observation of Forney [25] that growth of young walleyes in Oneida Lake, NY, was fairly constant from mid June to mid August but slowed significantly in September.

\subsection{Model of Predicted Catches}

\subsubsection{Size and Time Discretization}

The fish population was divided into $M$ non-overlapping, adjacent length classes and time was discretized into $K$ time points (indexed by $i$ and $n$ respectively), so that $N_{i, n}$ is the number of fish in Class $i$ at time $t_{n}$. The length classes were indexed in increasing order, the smallest being Class 1 . Both age and size-structured models of fish populations have been employed regularly in the past $[26,27,28,29]$, the former primarily when the modelling period is over several cycles of reproduction 
and age is the primary indicator of preproductive output. In this case we are more interested in size since our model will not include new recruits, and size is the determining factor for harvesting.

If the boundaries of the length classes remained constant over time, then some fish would be moving from one class to another as they grew. To avoid this complication, the length class boundaries were defined to increase as time increases at the same rate as the average fish growth, and the simplifying approximation that no fish cross the length class boundaries was imposed. More precisely, it was assumed the number of fast growing fish that cross the increasing boundary from length Class $i$ to length Class $i+1$ is equal to the number of slow growing fish in Class $i+1$ that are overtaken by the increasing boundary transferring them into Class $i$, so that on average the number of fish crossing the boundary is zero. Effectively then, the length classes grow with the fish and all fish remain within their length classes. Particularly, fish below the lowest length class boundary, $l_{\min }$, at the beginning of the study period are never considered even though some of them grow to be above length $l_{\text {min }}$ later in the study period. One length class boundary was always set exactly at the legal length limit (381 mm) between the end of the 1988 fishing season and the start of the 1989 fishing season (a period when there is no growth).

The time discretization was chosen in the following manner. Fishing trips were confined to one day but routinely trips by various anglers overlapped within each day. No attempt was made to order the trips within one day and all trips on any given day were always placed in the same time interval. For convenience, time points were chosen at the beginning and end of each fishing season. For the time spans between the start and end of the open fishing seasons, the maximum number of intervals into which the time span could be divided so that each interval had at least a prespecified minimum number of diary fishing hours, $h_{\min }$, was first determined. The time span was then divided into this number of intervals chosen so as to maintain the minimum number of fishing hours in each interval and minimize the variance in the number of fishing hours for the intervals. An analogous discretization scheme based on the number of diary fish caught rather than number of hours fished was also tried, but the results were similar.

The index pair $(i, n), 1 \leq i \leq M, 1 \leq n<K$, is defined as a fully harvestable cell if $\left[t_{n}, t_{n+1}\right)$ is within the fishing season and the lower boundary of Class $i$ at time $t_{n}$ is at or above the legal limit. If $\left[t_{n}, t_{n+1}\right)$ is within the fishing season and the lower boundary of Class $i$ at time $t_{n}$ is below the legal limit but the upper boundary at time $t_{n+1}$ is above the legal limit, then the pair $(i, n)$ is a partially harvestable cell. Otherwise the pair $(i, n)$ is nonharvestable. See Fig. 3. The discretization is chosen so that there is at most one partially harvestable cell in any time interval $\left[t_{n}, t_{n+1}\right)$. For harvestable cells $(i, n)$, the number of fish harvested from Class $i$ between $t_{n}$ and $t_{n+1}$ is

$$
H_{i, n}=N_{i, n}-N_{i, n+1} .
$$

For any cell, $C_{i, n}$ is defined as the predicted number of fish in Class $i$ caught by the diary anglers between time $t_{n}$ and time $t_{n+1}$. If $(i, n)$ is a partially harvestable cell, then $C_{i, n}^{\text {legal }}$ is defined to be the predicted number of legal length fish in Class $i$ caught by the diary anglers between time $t_{n}$ and time $t_{n+1}$.

\subsubsection{Basic Assumptions}

The model is based on the following underlying assumptions. For any given length class and given time interval, the number of fish harvested, $H_{i, n}$, is proportional to the predicted diary catch, $C_{i, n}$, and the predicted diary catch is proportional to the average population over the time interval in that 


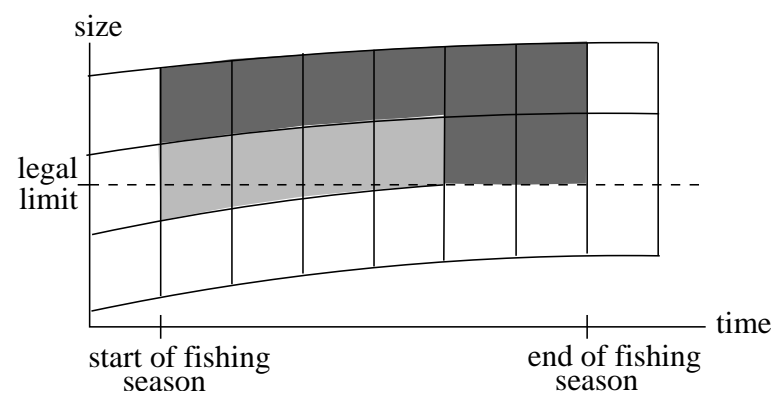

Figure 3: Length and time discretization. Solid lines indicate boundaries of cells. Dark grey cells are fully harvestable, light grey are partially harvestable, and white are nonharvestable.

size range. That is,

$$
H_{i, n}= \begin{cases}B_{i, n}^{C} C_{i, n}, & \text { if }(i, n) \text { is fully harvestable } \\ B_{i, n}^{C} C_{i, n}^{\text {legal }}, & \text { if }(i, n) \text { is partially harvestable }\end{cases}
$$

and

$$
C_{i, n}=B_{i, n}^{N}\left(N_{i, n}+N_{i, n+1}\right) / 2, \quad 1 \leq i \leq M, 1 \leq n<K
$$

where $B_{i, n}^{C}$ and $B_{i, n}^{N}$ are proportionality factors. ( $B^{N}$ might be called the catchability.) This assumption of a linear dependence between the fish population and the catch size is likely not completely valid, but determining the appropriate nonlinear response can at best be only partially determined from the catch distribution [30]. For simplicity, we maintain a linear relationship. Both factors $B$ are in general functions of length class and time, and account for variability due to many reasons such as feeding habits, availability of prey, spawning status, weather/water conditions, season of year, fisherman habits, etc. $B^{C}$ clearly varies over time since it depends on the total number of anglers compared to diary anglers at any time. Our data also clearly show variability of $B^{N}$ over time (see Sec. 4). Assumption (4) clearly requires a reasonably long time interval; one would not expect the length distribution of caught fish from a ten hour trip to resemble the length distribution in the lake, however, after about one hundred hours of fishing such an expectation may not be unreasonable. On the other hand, we do not want the time interval to be too long otherwise the proportionality factors in one time interval would not be well approximated by a constant. Note also that in (4) the population in cell $(i, n)$ is being approximated as the mean of the population in length Class $i$ at the beginning and the end of the time interval. In other words, the model is assuming that when harvesting occurs in cell $(i, n)$, it does so at a constant rate.

Since the functions $B$ are essentially completely unknown to us, they are eliminated by effectively considering ratios of catches, and assuming

$$
B_{i, n}^{C}=B_{i+1, n}^{C}, \quad(i, n) \text { and }(i+1, n) \text { are harvestable, }
$$

and

$$
B_{i, n}^{N}=B_{i+1, n}^{N}, \quad 1 \leq i<M, 1 \leq n<K .
$$

That is, for two adjacent length classes over a given time interval, the proportionality factors, $B^{N}$ are identical. The same is true for $B^{C}$ for two adjacent length classes that are both partially or fully 
harvestable. Thus if there are twice as many fish in Class $i$ as fish in Class $i+1$ over some given time interval, then the diary catch for Class $i$ is expected to be twice that of Class $i+1$.

Assumptions (5) and (6) are obviously questionable, but whether the factors $B$ would be better approximated as increasing or decreasing functions of size is not immediately clear. One could reasonably argue that the longer (older) fish that are present are simply the fish that are better at not being caught, hence $B^{N}$ should decrease as size increases. On the other hand, the fishermen, and particularly the diary fishermen, may well use methods to target larger fish more effectively than smaller ones and so $B^{N}$ should increase with size. If one argues that the diary fishermen are likely better at catching larger fish than the other fishermen, then $B^{C}$ should decrease with size, but if a fisherman is more likely to kill a larger fish than a smaller one, $B^{C}$ should increase with size. Because of these conflicting arguments regarding the dependence of the factors $B$ on length, and because some assumption must be made to eliminate these unknowns from consideration, we feel that assuming the factors $B$ are independent of length is reasonable. Note that these assumptions do not dictate that the proportionality factors are constant in time, for example, $B_{i, n}^{N}$ need not equal $B_{i, n+1}^{N}$.

\subsubsection{Constraints}

Since there are $M$ length classes and $K$ time points (thus $K-1$ time intervals), the model has $K M$ unknowns $N_{i, n},(K-1) M$ unknowns $C_{i, n}$, and $n p H$ unknowns $C_{i, n}^{\text {legal }}$, where $n p H$ is the total number of partially harvestable cells. These unknowns are subject to the following constraints.

For nonharvestable cells $(i, n)$, the population remains unchanged over the cell time interval, while for harvestable ones the harvest must be nonnegative:

$$
\begin{array}{ll}
N_{i, n}=N_{i, n+1}, & \text { if }(i, n) \text { is nonharvestable } \\
N_{i, n} \geq N_{i, n+1}, & \text { if }(i, n) \text { is harvestable }
\end{array}
$$

Assumptions (4) and (6) imply that every cell $(i, n)$ satisfies

$$
\frac{C_{i, n}}{\left(N_{i, n}+N_{i, n+1}\right) / 2}=\frac{C_{i+1, n}}{\left(N_{i+1, n}+N_{i+1, n+1}\right) / 2},
$$

which may be written as

$$
C_{i+1, n}\left(N_{i, n}+N_{i, n+1}\right)=C_{i, n}\left(N_{i+1, n}+N_{i+1, n+1}\right), \quad 1 \leq i<M, 1 \leq n<K .
$$

Likewise, assumptions (3) and (5) imply that each adjacent pair of fully harvestable cells, $(i, n)$ and $(i+1, n)$, satisfies

$$
\frac{H_{i, n}}{C_{i, n}}=\frac{H_{i+1, n}}{C_{i+1, n}}
$$

which, using (2), may be written as

$$
C_{i+1, n}\left(N_{i, n}-N_{i, n+1}\right)=C_{i, n}\left(N_{i+1, n}-N_{i+1, n+1}\right), \quad(i, n) \text { and }(i+1, n) \text { are fully harvestable, }
$$

and similarly

$$
C_{i+1, n}\left(N_{i, n}-N_{i, n+1}\right)=C_{i, n}^{\text {legal }}\left(N_{i+1, n}-N_{i+1, n+1}\right),
$$

$(i, n)$ is partially harvestable. 
In addition, for partially harvestable cells $(i, n)$, only the legal length fish are allowed to be harvested and it is further imposed that the ratio of the legal catch to the full catch must be equal to the ratio of the legal fish to the full number of fish in the cell. This is achieved by assuming that the length distribution of fish in Class $i$ at the start of the fishing season is uniform. This assumption only applies to the class that straddles the legal length limit and is likely reasonable since the class was never previously harvested from at the start of the season. With this assumption we are able to prevent the model from allowing all of the fish in a partially harvestable cell from being harvested immediately. In particular, for a partially harvestable cell, $(i, n)$, the number of sublegal length fish at $t_{n+1}$ is given by

$$
N_{i, n+1}^{\text {sublegal }}=S_{i, n+1} N_{i, n_{s}}, \quad \text { where } \quad S_{i, n+1}=\frac{\text { sublegal length span of Class } i \text { at } t_{n+1}}{\text { full length span of Class } i \text { at } t_{n+1}},
$$

and $n_{s}$ is the start of the fishing season. For example, if Class $i$ at time $t_{n+1}$ ranges from 350 to $400 \mathrm{~mm}$ where the legal length is $381 \mathrm{~mm}$, then $N_{i, n+1}^{\text {sublegal }}=\frac{31}{50} N_{i, n_{s}}$. The restriction that only legal length fish can be harvested from a partially harvestable cell is then

$$
N_{i, n+1} \geq S_{i, n+1} N_{i, n_{s}}, \quad \text { if }(i, n) \text { is partially harvestable. }
$$

And the requirement that the ratio of the legal catch to the full catch be equal to the ratio of the legal fish to all the fish is, by (4)

$$
\frac{C_{i, n}^{\text {legal }}}{C_{i, n}}=\frac{B_{i, n}^{N}\left(N_{i, n}-S_{i, n} N_{i, n_{s}}+N_{i, n+1}-S_{i, n+1} N_{i, n_{s}}\right) / 2}{B_{i, n}^{N}\left(N_{i, n}+N_{i, n+1}\right) / 2}
$$

which can be written as

$$
C_{i, n}^{\text {legal }}\left(N_{i, n}+N_{i, n+1}\right)=C_{i, n}\left(N_{i, n}+N_{i, n+1}-\left(S_{i, n}+S_{i, n+1}\right) N_{i, n_{s}}\right),
$$

$(i, n)$ is partially harvestable.

Since the model effectively compares ratios of catches, the values of $N_{i, n}$ could all be scaled by some factor without affecting the ratios. To obtain concrete values for the fish population it is necessary to have an estimate for the population at some time $t_{n_{e}}$. This is provided by the mark and recapture data from 1989. From these data, the total walleye population of age 2 and older fish in the spring of 1989 was estimated to be 16,824 of which only 2,831 were legal size (above $381 \mathrm{~mm}$ ). The length distribution below legal size is assumed to be approximately uniform and includes all fish down to $229 \mathrm{~mm}$ (nine inches) in size. The mean length of age two fish from Canadarago Lake in 1989 was $243 \mathrm{~mm}$. Taking the time point $t_{n_{e}}$ as the last time point before the start of the 1989 fishing season, these data impose the constraints

$$
\sum_{i=i_{L}}^{M} N_{i, n_{e}}=2831
$$

and

$$
\sum_{i=1}^{i_{L}-1} N_{i, n_{e}}=(16824-2831) \frac{381-\text { lowest boundary at } t_{n_{e}}}{381-229},
$$

where $i_{L}$ is the smallest legal class at time $t_{n_{e}}$. (Recall that the discretization is set up so that between the 1988 and 1989 fishing seasons a length class boundary exists exactly at the legal limit.) 


\subsubsection{Fitting the Model}

Fitting the model of the predicted catches, $C_{i, n}$ consists of the following two steps.

- Choosing a time and length class discretization.

- Choosing all values of $N_{i, n}, C_{i, n}$ and $C_{i, n}^{\text {legal }}$ subject to the constraints (7)-(15) such that the quantity

$$
\sum_{i=1}^{M} \sum_{n=1}^{K-1} w_{n}\left(C_{i, n}-D_{i, n}\right)^{2}
$$

is minimized, where $D_{i, n}$ is the number of fish in Class $i$ recorded as caught by the diary fishermen over the time interval $\left[t_{n}, t_{n+1}\right)$, and $w_{n}$ is a weighting factor described below.

The time discretization was chosen as outlined in Sec. 3.2.1 to minimize the variance in the number of fishing hours in each interval. However, since some days, especially holidays, had significantly more fishing effort than other days, and since no attempt was made to split up data from the same day, the intervals sometimes had substantially different numbers of fishing hours associated with them. In addition, if the small amount of data from prior to the open season was included, then the requirement that a time point exist at the start of the season made it so that the one time interval prior to the open season typically did not reach the minimum number of hours that the intervals within the open fishing season had. To allow for unequal amounts of fishing hours in each time interval the weighting function, $w_{n}$, was set to be equal to the number of diary fishing hours in the interval $\left[t_{n}, t_{n+1}\right)$ divided by the product of the total number of hours fished by diary anglers and the number of length classifications.

Numerical nonlinear optimization algorithms require an initial guess for the solution from which to start, this is also true for the MATLAB function "fmincon" which we used to perform the optimization. For many of the discretizations, the function (16) suffers from being somewhat flat with a number of local minima, so that the numerical software converges to different minimum values of the function depending on the initial condition from which it starts. These local minimum values were typically quite close to each other, but the corresponding optimal values for the variables $C_{i, n}$ and $C_{i, n}^{\text {legal }}$, and particularly $N_{i, n}$, were sometimes considerably distant from those obtained at a different local minimum. In an attempt to ascertain the global minimum, six different sets of initial conditions were selected and the solution that converged to the lowest minimum value for (16) was chosen. Our analysis indicated that the optimal solution so obtained was likely very close to the global minimum.

\section{Results}

Diary data collected from April until November in 1988 (very few trips were taken after Labour Day) and from April through June in 1989 were analyzed. No diary data were collected during the ice fishing season of 1988-89. The open season for walleye began on May 7, 1988, and on May 6, 1989.

The diary data exhibit a distinct decrease in both the length of caught walleye and catch rates for legal length walleye over the 1988 season. Fig. 4 shows a scatter plot of the length of caught walleye over 1988 and the first two months of the fishing season in 1989. Least squares fits of straight lines to the 1988 and 1989 (whole season) diary data are also shown. The line for 1988 has a decrease of $17.8 \mathrm{~mm}$ per month while the 1989 line has an increase of $6.6 \mathrm{~mm}$ per month. The mean length of caught fish decreases about $95 \mathrm{~mm}$ from May 1988 to May 1989. Fig. 5 shows a histogram for the number of walleye caught in each month, divided into legal and sublegal categories. From this figure 


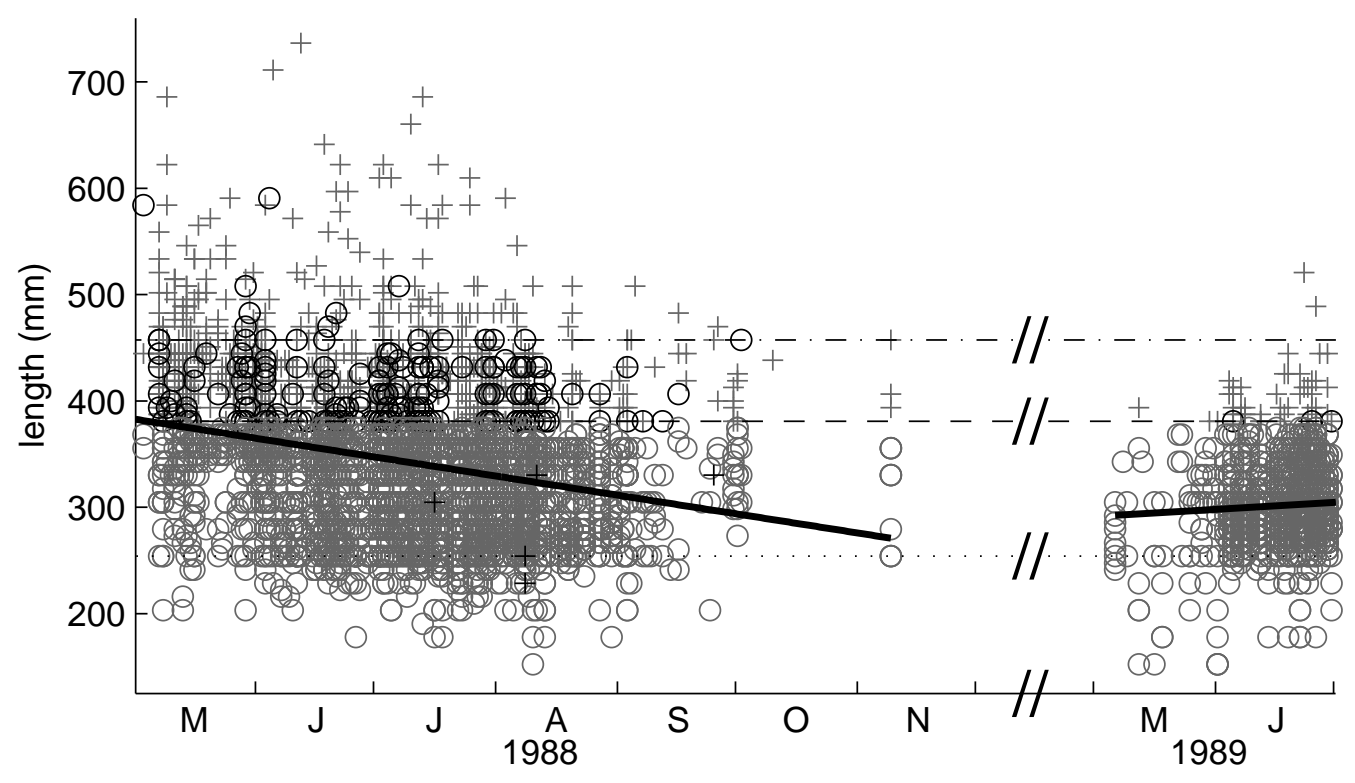

Figure 4: Length of caught fish. Crosses: killed; circles: released; dashed line: legal length, $381 \mathrm{~mm}$ (15 inches); dash-dot line: legal length prior to $1988,457 \mathrm{~mm}$ (18 inches); dotted line: $254 \mathrm{~mm}$ (10 inches). Legal length fish that were released and sublegal length fish that were killed are marked in a darker colour. The solid lines are best linear fits of the 1988 and 1989 data respectively.

it is clear that the diary fishermen caught considerably more fish in July 1988, but this was mostly due to an increase in the number of sublegal length fish. The number of legal length fish caught in the months of May, June and July 1988 did not change considerably. However, almost no legal length fish were caught in May and June of 1989. Fig. 6 shows the number of fishing hours recorded by the diary fishermen each month. The monthly catch rates (\# of fish caught per hour) are shown in Fig. 7. Note that since very little data was collected in October and November of 1988 (19 fish caught in 48 hours, and 14 fish caught in 12 hours), the catch rates for these two months should be regarded lightly. The prominent feature is that the catch rate for sublegal length fish shows a rise and fall over the summer, while that for the legal length fish shows a steady decrease.

Fig. 7 also provides evidence for the variability of $B^{N}$ (the ratio of the predicted catch to the number of walleye) over time. Since the catch rate of sublegal fish (which are not being harvested only three of these were reported killed) drops substantially after August, either $B^{N}$ is varying over time or a huge percentage of these fish are growing into legal size late in the season. However, if such a large percentage were growing to legal length, one would expect to see an increase in the catch rate for legal fish, which is not apparent. In addition, the growth data (Fig. 1) indicate that yearly growth was only about $20 \mathrm{~mm}$ per year for fish near the legal size limit, so that relatively few sublegal fish should be attaining legal size over the season.

$B^{N}$ may also vary according to fish size. It has been shown that angler catch rate is inversely related to prey availability $[31,6]$, and in general prey availability would vary if the size of the predator 


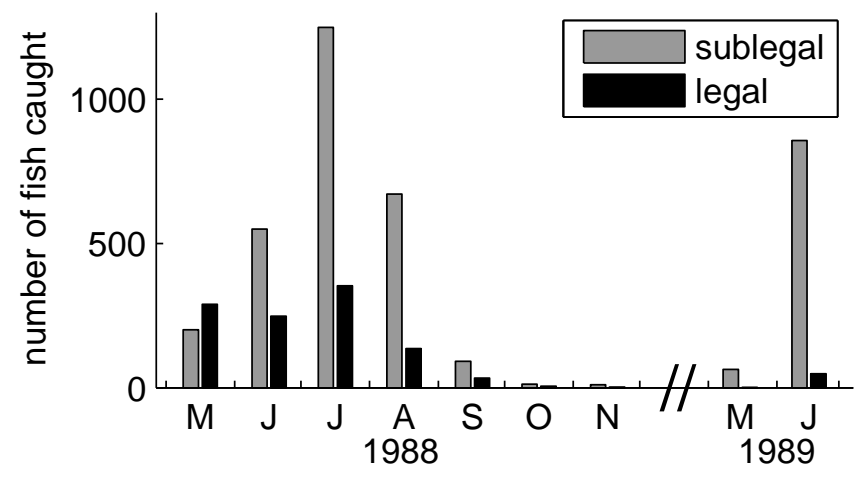

Figure 5: Number of fish caught each month. Gray: sublegal length; black: legal length.

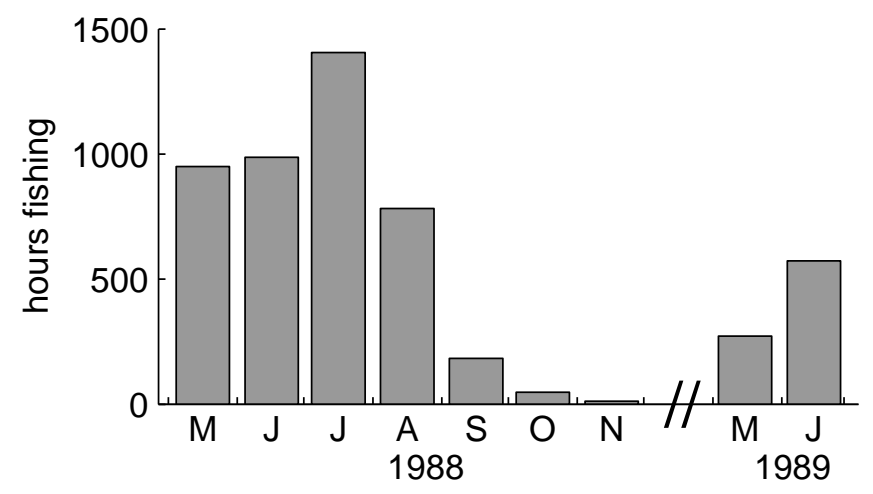

Figure 6: Fishing hours each month.

determined the size of its prey. However, in Oneida Lake where yellow perch are the preferred and primary prey of walleyes, most walleye above young of the year size depend on essentially the same prey: yearling perch up until mid to late June, and then they switch to young of the year perch when they reach about $18 \mathrm{~mm}$. If all the perch are consumed then the walleye switch to young of the year walleye as prey [23]. Yellow perch were also the dominant prey species in Canadarago Lake. Beginning in 1987 mean zooplankton size increased substantially within a month or two of when young of the year perch reached $18 \mathrm{~mm}$, indicating that walleye had considerably reduced the perch year class. After 1986 there were only very weak year classes of walleye produced until 1993 and 1995 (unpublished data, Cornell University Biological Field Station). In the extreme situation where there are few if any young of the year fish (or small size adult fish like shiners), the larger walleye would be more likely to find food since they can eat larger prey, resulting in a larger catch rate of small adult walleye than larger walleye. There are also other reasonable mechanisms by which catch rates at a given time for walleye will vary with the size.

Our base case time and length class discretization was one where time intervals were chosen to 


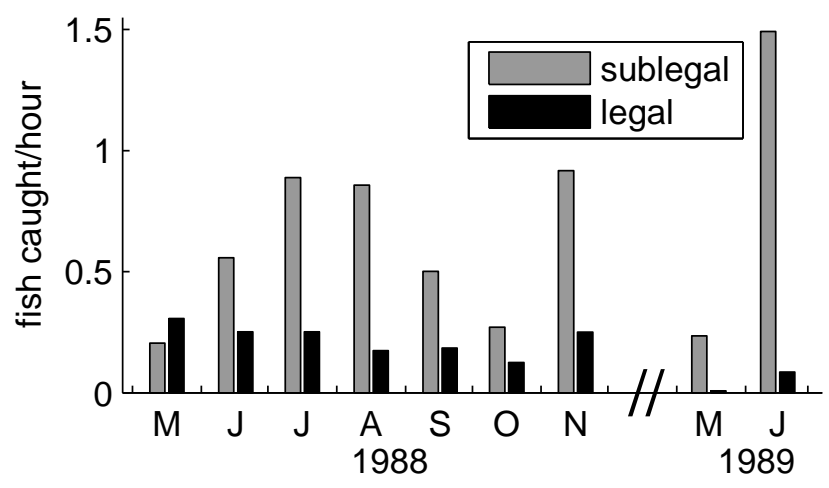

Figure 7: Monthly catch rates. Rates for October and November of 1988 are based on just 48 and 12 fishing hours respectively.

have at least 100 fishing hours where possible, and five length classes were chosen so that the lower boundaries between the two fishing seasons were at 283, 332, 381, 430, and $479 \mathrm{~mm}$. We felt that this was a reasonable discretization scheme, neither too fine nor too gross, but we also analyzed other discretizations, as described below, to determine the variability in the results. Boundaries between length classes throughout the years were then obtained using the daily fraction of annual growth (Fig. 2). Choosing the lowest length class at $283 \mathrm{~mm}$ in the spring of 1989 resulted in a minimum length of $254 \mathrm{~mm}$ at the start of 1988. In Fig. 4 (dotted line) it is clear that as one decreases past $254 \mathrm{~mm}$ (10 inches) there is a significant decrease in the number of reported fish caught. It is possible that diary fishermen did not report all fish below the 10 inch level for psychological reasons, or that fish below 10 inches were simply discriminated against by the fishing methods employed. In any event, we felt it best to not include data for fish below $254 \mathrm{~mm}$. The base case length and time discretization is plotted in Fig. 8 and the time values and number of hours fishing in each interval are given in Tab. 1. We emphasize that this particular time and length class discretization is not necessarily the best in any sense. We felt that 100 hours of diary fishing effort was likely long enough for the basic assumption that the length distribution of caught fish reflects the length distribution of fish in the lake to be valid, and short enough to neither discard too much information nor call into question the assumption that the proportionality factors $B$ remain constant over the time interval. As we show below and discuss more in Section 5, the precise choice of time discretization is not too important. The number of length class distributions is more important and it turns out that five seems to be a fairly reasonable number as we show below.

With this base case discretization, the minimum value of (16) was 51.32 achieved with a fish population as shown in Fig. 9. From this figure it can be seen that the model is best fit when there is a large reduction in legal fish from the end of May to early June 1988. (Memorial Day was May 30 in 1988). The total number of fish harvested in 1988 in this model is 14,869 and an additional 3,271 were harvested in May and June of 1989. Although the model allows for fish to be harvested during the 1988-89 ice fishing season, the optimal fit for the base case discretization (and indeed most of the discretizations) shows no decrease in the population over the winter. The reason for this is two-fold. First, there is no data from the ice fishing season and so no immediate driving force for the harvest to 


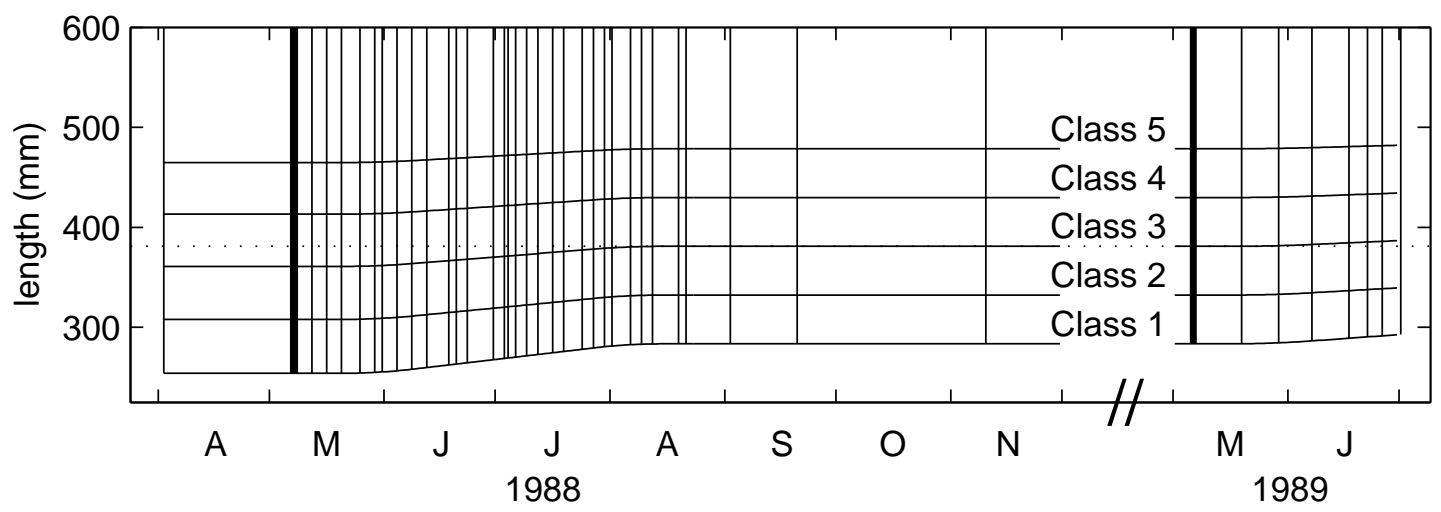

Figure 8: Base case length and time discretization. Bold lines are the start of the fishing seasons, dotted line is legal length $(381 \mathrm{~mm})$.

be nonzero, and secondly, the mark and capture data dictate that 2831 of the total 16,824 fish in the spring of 1989 are legal length, a much higher ratio than the diary catch data from May and June of 1989 would suggest. As a result, the model optimizes by keeping the population constant throughout the winter and then harvesting virtually all these remaining legal length fish in May and June of 1989.

Exploitation is defined as the the fraction of walleye that were legal length in the spring of 1988 which were harvested in the 1988 open water fishing season. For the base case discretization, the relevant populations of each class at the start and end of the 1988 season as determined by the model are given in Tab. 2. In this table, $x$ is the number of walleye in Class 3 that were initially sublegal length in the spring of 1988 and that survived until the end of 1988 . The model does not determine whether any particular fish harvested from Class 3 was initially sublegal or legal length at the beginning of 1988, hence the value of $x$ lies somewhere between 0 (all fish in Class 3 at the end of 1988 were initially legal length) and 2029 (all fish in Class 3 at the end of 1988 were initially sublegal). Thus exploitation, $\mu$, is in the range,

$$
\frac{12025}{14856}=0.809 \leq \mu \leq \frac{12025+2029}{14856}=0.946
$$

More reasonably, $x$ is somewhere between these two extremes. If it is assumed that throughout the season the harvest from Class 3 is proportionally divided between the remaining fish that were originally legal length and the available fish that have grown to legal length, then $x$ can be calculated from the model output to be 1676 , hence

$$
\mu \approx \frac{12025+1676}{14856}=0.922
$$

In any event, the exploitation was very high, between about 81 and 95 percent and this is for the open water season only.

The 1988 predicted harvest and exploitation rates were affected by the choice of time and length class discretization as well as whether or not the data from 1989 was included in the optimization. Fig. 10 shows the different harvest estimates obtained depending on various choices for these parameters. Choice of length class discretization had the greatest effect on the predicted 1988 harvest. As the 
Table 1: Base case time discretization and diary fishing hours in each time interval.

\begin{tabular}{ccccc} 
Date $\left(t_{n}\right)$ & $\begin{array}{c}\text { fishing time }[\mathrm{hr}: \mathbf{m i n}] \\
\text { in interval }\left[t_{n}, t_{n+1}\right)\end{array}$ & & Date $\left(t_{n}\right)$ & $\begin{array}{c}\text { fishing time }[\mathbf{h r}: \mathbf{m i n}] \\
\text { in interval }\left[t_{n}, t_{n+1}\right)\end{array}$ \\
\cline { 1 - 2 } \cline { 1 - 2 } 02 Apr 1988 & $71: 15$ & & 19 Jul 1988 & $109: 48$ \\
07 May 1988 & $125: 30$ & & 24 Jul 1988 & $124: 10$ \\
08 May 1988 & $123: 04$ & & 27 Jul 1988 & $115: 14$ \\
12 May 1988 & $120: 20$ & & 30 Jul 1988 & $126: 55$ \\
16 May 1988 & $109: 40$ & & 01 Aug 1988 & $142: 08$ \\
20 May 1988 & $121: 30$ & & 06 Aug 1988 & $129: 19$ \\
25 May 1988 & $119: 35$ & & 09 Aug 1988 & $126: 34$ \\
29 May 1988 & $156: 50$ & & 12 Aug 1988 & $107: 37$ \\
31 May 1988 & $103: 40$ & & 19 Aug 1988 & $126: 12$ \\
04 Jun 1988 & $133: 37$ & & 21 Aug 1988 & $101: 33$ \\
08 Jun 1988 & $112: 07$ & & 02 Sep 1988 & $104: 31$ \\
12 Jun 1988 & $151: 23$ & & 20 Sep 1988 & $103: 46$ \\
18 Jun 1988 & $148: 41$ & & 10 Nov 1988 & $0: 00$ \\
20 Jun 1988 & $140: 19$ & & 01 Apr 1989 & $21: 00$ \\
23 Jun 1988 & $130: 30$ & & 06 May 1989 & $117: 27$ \\
30 Jun 1988 & $141: 50$ & & 19 May 1989 & $119: 25$ \\
03 Jul 1988 & $124: 39$ & & 29 May 1989 & $112: 35$ \\
04 Jul 1988 & $138: 15$ & & 07 Jun 1989 & $107: 43$ \\
06 Jul 1988 & $148: 10$ & & 17 Jun 1989 & $103: 46$ \\
09 Jul 1988 & $143: 37$ & & 22 Jun 1989 & $118: 47$ \\
12 Jul 1988 & $107: 16$ & & 26 Jun 1989 & $146: 04$ \\
16 Jul 1988 & $113: 07$ & 01 Jul 1989 &
\end{tabular}

number of length classes is increased, the predicted 1988 harvest generally decreases. For example, using the base case of 100 minimum diary fishing hours, the predicted harvest drops from 18,058 to 13,529 (a decrease of 25\%) when the number of classes is increased from three to seven. Increasing the minimum number of diary fishing hours (thus decreasing the number of time intervals) had less of an effect, causing variations in the harvest of about $13-16 \%$, all other parameters being equal. This effect was not monotonic; increasing $h_{\min }$ sometimes increased the harvest and sometimes decreased it, but the lowest values of the harvest always occurred with $h_{\min }=75$ or $h_{\min }=100$. Eliminating the 1989 data had very little effect on the 1988 harvest estimate when only three length classes were used, but generally decreased it when five or seven length classes were used. In all cases this effect was usually less than a 7\% change. The exploitation rate for these various discretizations is shown in Tab. 3. As is readily apparent from this table, exploitation ranges are not substantially changed when the minimum diary hours per time interval is altered or the 1989 data is excluded. However, changes in the number of length classes do affect these ranges. The upper ends of these ranges decrease as the number of length classes increase, and the lower ends also decrease, although this latter effect is minimal when increasing from five to seven classes.

The growth parameters are: the minimum temperature at which growth starts, $T_{\text {on }}$; the temper- 


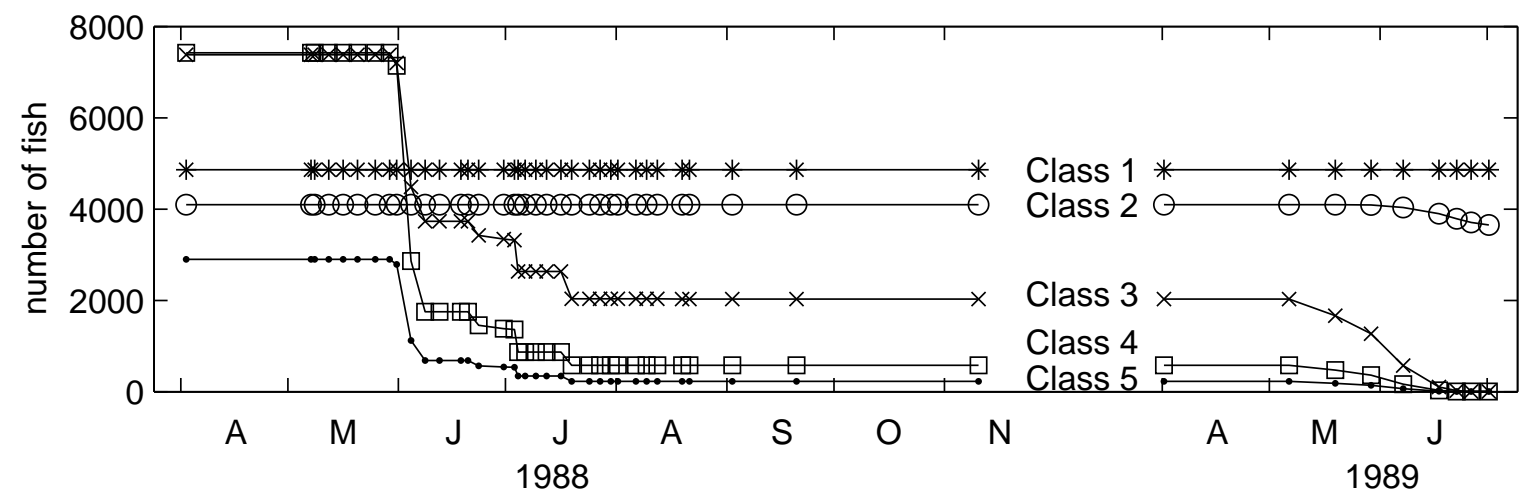

Figure 9: Model fish populations for the base case discretization.

Table 2: 1988 walleye harvest for the base case discretization.

\begin{tabular}{lrrrrrr} 
date & Class 3(IS) & Class 3(IL) & ${\text { Class } 4^{\dagger}}$ & ${\text { Class } 5^{\dagger}}^{\dagger}$ & total & total(IL) \\
\hline 7 May & 2844 & 4535 & 7422 & 2899 & 17700 & 14856 \\
10 Nov. & $x^{\ddagger}$ & $2029-x$ & 577 & 225 & 2831 & $2831-x$ \\
harvest & $2844-x$ & $2506+x$ & 6845 & 2674 & 14869 & $12025+x$
\end{tabular}

* IS=Initially sublegal: less than $381 \mathrm{~mm}$ in spring 1988. IL=Initially legal.

$\dagger$ All fish in Classes 4 and 5 are initially legal.

¥ All 2844 Class 3(IS) fish grow to legal length during 1988; $x$ is the number of these that survive until the end of 1988 . The total Class 3 population from the model at the end of 1988 was 2029.

ature above which growth is maximal, $T_{\max }$; the size of zooplankton below which there are sufficient perch and hence no growth limitation for walleye, $S_{\min }$; and the size of zooplankton above which there are no perch and hence no growth for walleye, $S_{\text {off }}$. These parameters were set to base case values of $T_{\text {on }}=12.8 \mathrm{C}, T_{\max }=19 \mathrm{C}, S_{\min }=7.5 \mathrm{~mm}$, and $S_{\text {off }}=8.5 \mathrm{~mm}$, and used as described in Sec. 3.1 to determine the daily fraction of annual growth throughout the year. Fig. 11 shows the predicted 1988 harvest using the base case time and length discretization but varying one of the growth parameters as indicated. Over the fairly wide ranges for each of these parameters, the predicted 1988 harvest changed by about $\pm 8 \%$ from the base case. The exploitation ranges for all of these trials were not substantially different from the base case range of $81-95 \%$. At most the bounds were shifted down by two percentage points.

As a test to see check if the algorithm as implemented in MATLAB was in fact finding a reasonably optimal solution from the six sets of initial conditions we were using, we tested it by taking the output of the model from the base case discretization and then using these predicted catches as input data. If the algorithm was perfect (and not halted when it achieves small tolerance levels in the objective function or gradients) it should have converged to exactly match this input data with the value of the objective function, (16), being zero. From the six initial conditions, the best value of the objective function obtained was $4.18 \times 10^{-4}$ (the algorithm halted since continued improvement was below the specified tolerance levels), with a corresponding 1988 harvest of 14,899 (just 30 larger than the true 


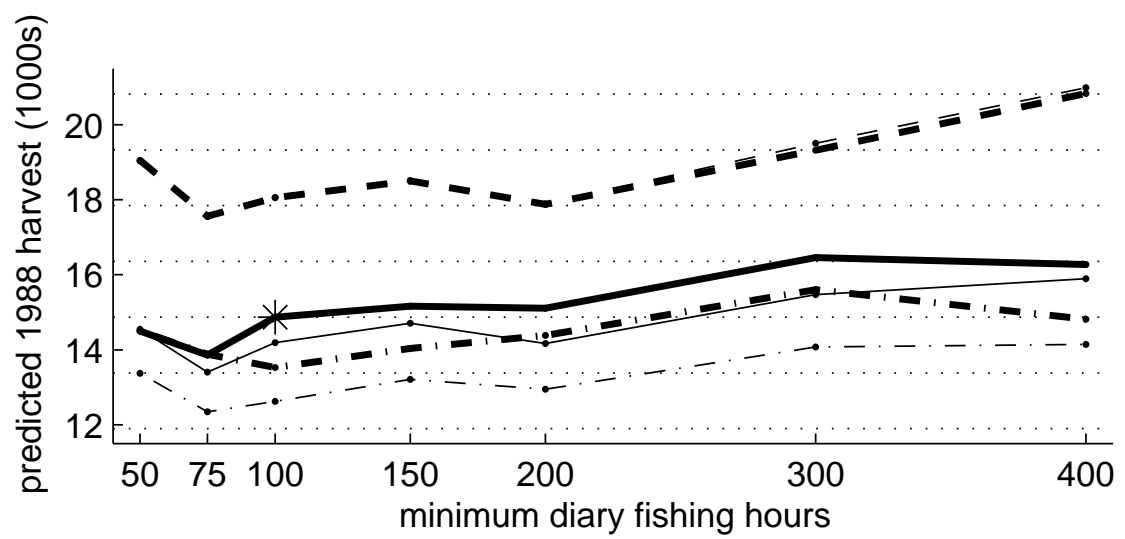

Figure 10: Predicted 1988 harvest for various discretizations. The horizontal axis gives the minimum number of diary fishing hours, $h_{\mathrm{min}}$, in each cell. Different line types indicate discretizations with different numbers of length classes: dashed - three length classes whose lower boundaries in the spring of 1989 are 283, 381 and $479 \mathrm{~mm}$; solid - five length classes at 283, 332, 381, 430 and $479 \mathrm{~mm}$; dash-dot - seven length classes at 283, 316, 348, 381, 414, 446 and $479 \mathrm{~mm}$. Thick lines are for discretizations that include the 1989 data while thin lines are with the 1989 data ignored. The base case discretization is marked with an asterisk and the dotted horizontal lines indicate differences from the base case by multiples of $10 \%$. The two dashed lines are nearly coincident and difficult to distinguish on this graph.

value from the base case input data). The output predicted catch data is of course not integer valued. If we first rounded the base case predicted catch data to the nearest integer before using it as input, then the algorithm terminated with an objective function value of $3.27 \times 10^{-2}$ and a 1988 harvest $4 \%$ larger than the true value. These objective function values should be compared with the typical values we obtained when fitting the diary data; the base case gave 51.32 and virtually all of the cases where of that magnitude. Thus there are about five orders of magnitude difference in the objective function from the best case of about $10^{-4}$ obtained from "perfect" data to the values obtained on the real data. Since two of these orders of magnitude are explained by simply rounding the "perfect" data, this indicates that the real data is reasonably well fit by the model, especially given the relatively gross assumptions underlying it. It also indicates that the algorithm is likely finding nearly optimal solutions from the initial conditions we provided it.

To gauge the sensitivity of the procedure to the diary data, a set of simulations were performed where a specified percentage (either 5 or 10 ) of the diary fish in the discretization were randomly selected and then randomly placed into another cell. Ten realizations for both $5 \%$ selection and $10 \%$ selection were performed using the base case discretization; the results are indicated in Tab. 4. These data indicate that altering the size and date classification of even as many as $10 \%$ of the fish resulted in harvest estimates on average only about $4 \%$ different than the base case, 14,869. And exploitation rates are virtually unchanged. 
Table 3: Exploitation rates (\%) for various discretizations. The upper and lower range sets correspond to including and excluding the 1989 data respectively.

\begin{tabular}{lccccccc} 
length class lower & \multicolumn{7}{c}{ minimum diary fishing hours, $h_{\min }$} \\
\cline { 2 - 8 } $\begin{array}{l}\text { boundaries in } \\
\text { spring 1989 (mm) }\end{array}$ & 50 & 75 & 100 & 150 & 200 & 300 & 400 \\
\hline $283,381,479$ & $85-99$ & $83-99$ & $84-99$ & $84-99$ & $84-99$ & $84-99$ & $86-99$ \\
& $85-99$ & $83-99$ & $84-99$ & $84-99$ & $84-99$ & $84-99$ & $86-99$ \\
$283,332,381$, & $81-94$ & $80-94$ & $81-95$ & $81-95$ & $81-94$ & $82-94$ & $83-95$ \\
430,479 & $81-94$ & $79-94$ & $80-94$ & $81-94$ & $80-94$ & $81-94$ & $81-94$ \\
$283,316,348,381$, & $81-92$ & $80-91$ & $80-91$ & $81-91$ & $80-91$ & $80-91$ & $80-91$ \\
$414,446,479$ & $80-91$ & $78-90$ & $79-90$ & $80-90$ & $78-90$ & $79-90$ & $80-90$
\end{tabular}

Table 4: Sensitivity of the predicted 1988 harvest and exploitation rate to the diary data. Ten realizations were performed where the given percentage of fish were randomly altered in their size and time caught. Means \pm standard deviations are reported.

\begin{tabular}{crr} 
alteration & 1988 harvest & exploitation range (\%) \\
\hline $5 \%$ & $14,307 \pm 411$ & $80.25 \pm 0.50-94.30 \pm 0.26$ \\
$10 \%$ & $14,269 \pm 814$ & $80.15 \pm 0.96-94.36 \pm 0.48$
\end{tabular}

\section{Discussion}

The most appropriate discretization scheme, both in time and length, that one should use is not completely clear. On the one hand, if the discretization is too coarse, information in the data is being discarded, and on the other hand, if the discretization is too fine, the signal to noise ratio in the data becomes too small, and the numerical optimization problem becomes larger in size and hence more difficult. The validity of the method's underlying assumptions is also influenced by the discretization. If the time interval is too small then it is not likely that the length distribution of the fish caught in that interval reflects the length distribution in the lake, but it is not clear what size the interval needs to be in order for these distributions to be reasonably close. Conversely, if the time or length interval is too large, the assumption that the catchability in Class $i$ over the interval $\left[t_{n}, t_{n+1}\right), B_{i, n}^{N}$, is equal to that of Class $i+1, B_{i+1, n}^{N}$, is less likely to hold. Similar statements could be made about the assumption that $B_{i, n}^{C}$, the ratio of the harvest in Class $i$ to the diary catch in the interval $\left[t_{n}, t_{n+1}\right)$, is equal to that of Class $i+1$.

Given these uncertainties, it is remarkable that the estimate of the 1988 harvest is as insensitive to the time discretization as the results indicate. For a given length class discretization, varying the minimum number of diary fishing hours in a time interval from 50 to 400 resulted in estimates that were only $13-16 \%$ different. If the minimum fishing hours were varied from 50 to only 200 , then this difference was only about $6-8 \%$.

The length class discretization had more of an effect on the estimated 1988 harvest than the time discretization. Generally, the fewer the number of length classes, the greater the harvest estimate. 

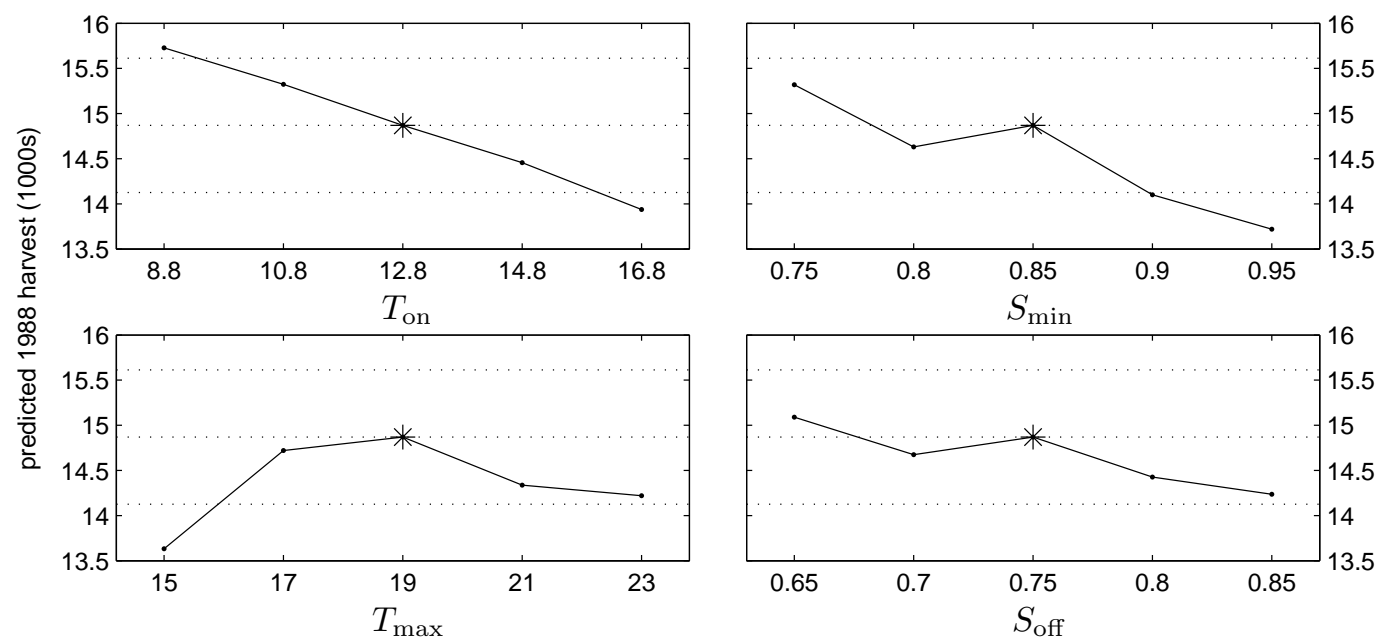

Figure 11: Sensitivity of the predicted 1988 harvest to changes in the growth parameters. Each of the four plots shows changes in the estimated harvest when one of the growth parameters is varied around its base case value (marked with asterisk). All other parameters are held at their base case. Dotted lines indicate differences from the base case by multiples of $5 \%$.

But, there were considerably more differences between the discretizations with just three classes and the ones with five (18-31\%) compared to the differences between the ones with five and seven (0-9\%); see Fig. 10. Estimates of the harvest with three length classes were around 19,000 fish while for five or seven classes were around 15,000. In particular, for 100 minimum fishing hours, the 3-class discretization had a 1988 harvest of 18,058 fish while the 5-class discretization (the base case) was 14,869. To see if this large discrepancy could be accounted for due to smaller class sizes in the legal length spans or the sublegal length spans, we tested two 4-class discretizations. The first of these combined the bottom two classes of the base case 5-class discretization, while the second combined classes 3 and 4 of the base case. Specifically, the lower boundaries of the classes in the spring of 1989 were 283, 381, 430, and $479 \mathrm{~mm}$ for the first discretization, and 283, 332, 381, and $479 \mathrm{~mm}$ for the second. In the first test, the predicted 1988 harvest was 14,969 fish, and the fish population throughout the year was almost identical to the base case. In the second test the predicted 1988 harvest was 16,688 and the population in the third class (corresponding the classes 3 and 4 of the base case) accounted for most of the increase in harvested fish over the base case. It appears from these results that the finer resolution of length classes among legal length fish is possibly more important than among sublegal length fish, but that, in any event, having more length classes constrains the harvest from being too large.

The fact that the predicted fish population for the base case (Fig. 9), and indeed for most of the discretizations we used, show a nearly constant amount of fish until the end of May 1988 can be partly explained by the observation that the data exhibit an unexpectedly small number of sublegal length fish caught at the beginning of the 1988 season (see Figs. 4 and 5). The large drop in the ratio of legal to sublegal length fish caught going from May to June dictates a substantial harvest effect. The data throughout May would actually be best fit by having less legal length fish than in June, but 
since growth is not occurring in May there cannot possibly be an increase in legal length fish. The optimization scheme settles for the best alternative, being a constant level of fish in May. We could impose minimum harvests on the model as the number of diary fish killed but such restrictions would not likely alter the results significantly.

The diary data extend into 1989, and clearly show the lack of legal length fish in that year. The fish population estimate obtained from the mark and capture data was for the spring (May) of 1989. It was not immediately clear whether including the 1989 diary data in the model would be beneficial or not. Certainly, it increases the computation time since more data is being processed. On some of the tests, we included data from May and June of 1989, but the effect on the predicted 1988 harvest was not very substantial. Essentially, excluding the 1989 data removed some constraints, particularly on the sublegal population sizes, and this resulted in mildly lower 1988 harvest estimates.

Exploitation of walleye during the open water season in 1988 was extremely high, in the range of 0.81 to 0.95 . While the population of legal length walleyes had been radically reduced by the end of the open water fishing season in November 1988, an additional but unknown harvest would have occurred during the winter 1988-89 ice fishing season that closed on March 15, 1989 (no diary data was collected from ice fishermen). Based on counts of anglers made by DEC from airplanes, $21 \%$ of the total fishing effort during the spring 1988 through March 1989 period occurred during the ice fishery [3]. Exploitation in 1988-89 was $>7$ to as high as 19 times greater than in 1989-90, when exploitation was estimated to be 0.05 to 0.11 [3]. Total exploitation was well above the $0.06-0.47$ exploitation rates cited by Schneider [32] for northern walleye populations. While about one fifth of the fishing effort for Spring 1988 through March 1989 occurred during the ice fishing season, numbers of walleye harvested were probably low since a large proportion of the legal length walleye had already been removed. The low numbers of walleye harvested in spring 1989 supports this conclusion as does the fact that the optimal fits we obtained showed little or no harvest through the ice fishing season. As we indicated earlier, the minimal ice fishing harvest predicted by the optimal fits is partly due to the fact that the mark and recapture population estimates for legal length fish in the Spring 1989 are higher than the diary data from Spring 1989 would predict. Forced to have higher than desired legal length populations in the Spring of 1989, the algorithm compensates by predicting virtually no harvest in the previous winter.

The model shows a very large reduction in legal length fish in May and June near the beginning of the 1988 open water season Fig. 9. Schneider [33] reported extremely high exploitation of several species of fish the first three days Mill Lake, Michigan, was opened to fishing after a five year period when the lake was closed to fishing. While Canadarago Lake had not been closed to fishing prior to 1988, the developing walleye fishery had begun attracting the attention of anglers. Since about 1985 anglers were catching numbers of walleye in excess of $500 \mathrm{~mm}$ and the reduction in the minimum size limit from 457 to $381 \mathrm{~mm}$ beginning on opening day in May 1988 had been well publicized. The next closest substantial walleye fishery was Oneida Lake, $73 \mathrm{~km}$ to the northwest. The fishery had been attracting anglers from neighbouring states more than $160 \mathrm{~km}$ away [3].

Fishing effort (total hours) was very high during the period from May 1988 through the close of the ice fishing season in March 1989. No creel survey was conducted during this period but the DEC made counts of anglers from airplanes from spring 1988 through March 1991 [3]. Effort estimated from counts from airplanes were much higher than that estimated by angler interviews and counts of anglers from boats during the 1973-76 period [6] and during the spring 1989 - March 1991 period [3]. Airplane counts conducted from May 1988 through March 1991 followed the same procedure and frequency and served as an index of effort. Fishing effort in 1988-89 was forty-eight percent higher than it was from spring 1989 through March 1990 and sixty-eight percent higher than spring 1990 
through March 1991. Fishing effort during the 1973-76 period was similar to that experienced in 1990-91. This suggests that anglers had responded to the developing fishery and the anticipated fishery in 1988-89 and then made fewer trips after winter 1988-89 as angling success declined.

While exploitation of walleye seems excessively high at Canadarago Lake during 1988, the $17.8 \mathrm{~mm}$ reduction in average size per month of all walleye caught (including those fish released) by diary cooperators that first attracted our interest in determining exploitation, suggests that exploitation had to be very high. Additional evidence was the high catch rate of diary cooperators targeting walleye in 1988: 0.95 walleye/hour of all size fish and 0.29 legal length walleye/hour [3]. Diary cooperators harvested seventy-five percent of the legal length walleye they caught. A mode of $0.11-$ 0.15 walleye/hour range was cited by Colby et al. [14] and 17 of the 18 estimates were below 0.35 fish/hour. A four-fold decline in catch rates by diary cooperators of legal length walleye from 1988 to 1989 also suggests large numbers of fish were being removed [3].

The model developed in this paper demonstrates another use of fishery information collected by anglers. Diary programs are a relatively inexpensive means of monitoring and obtaining information about a fishery compared to traditional fisheries sampling methods [7]. The information provided here by anglers requires a well run program consisting of a group of trained and reliable anglers. From the model's standpoint, more diary information is better, and it is best if it is spread out over the season; for example, in this study, diary data from the winter ice-fishing season would have been helpful. It is important that the diary information include the type of fish for which the angler is fishing in order to isolate relevant data for specific species. Finally, it is also imperative that all fish caught are recorded, even sublegal length fish, since they essentially form a base to which catches of longer fish can be compared.

Both this study and the high exploitation rate of fish in Mill Lake, Michigan [33] suggests fishery management agencies need to carefully consider the potential affects of major changes in fishing regulations. Waters considered a potential for major regulation changes should be evaluated prior to and following the implementation of changes. Under the existing population status in Canadarago Lake in 1987, the pressing concern was preventing density dependent growth of walleye and other predator fish species. In this situation a substantial reduction in the walleye population was desirable, however, the reduction that occurred ended up being greater than anticipated. With all the possible variables that might influence the outcome of a fisheries regulation change, one could perhaps not expect to be very precise in controlling the outcome, however, radical regulation changes may best be phased in over a period of time. Phasing in a regulation change could be done progressively over a two to three year period by reducing the period of time fish can be harvested, by gradually changing minimum size limits, and/or gradually changing the number of fish that could be creeled daily. If such an approach had been applied to Canadarago Lake in 1988, the Lake would likely have enjoyed exceptionally good fishing from the anglers' viewpoint for several years rather than only one peak year, while still realizing DEC's goal of reducing predator fish populations to prevent density dependent growth sufficiently fast. The apparent extensive harvest that occurred over the Memorial Day weekend (the first long weekend after the new regulations were in place) indicates that holidays should also be considered when determining the timing of regulation changes since effort can be very high at such times. Other factors that might be considered, especially for walleye regulations, would be the presence or absence of strong or weak cohorts in the system with mean lengths less than the legal minimum length. Also walleye prey abundance might also affect walleye recruitment [23] and angler catch rates. Forney [31] showed that catch rates of walleye in Oneida Lake, New York, was inversely related to abundance of prey.

The introduction of a substantial population of walleye in Canadarago Lake radically altered the 
biomass of predators in the lake, resulting in significant reductions in the yellow perch population and increases in growth of perch in a relatively short period of time $[2,9,10]$. Changes in the fish population structure cascaded through the system, changing the zooplankton species dominance and size, resulting in increased water clarity in the lake [8]. The results were an improved fishery (more gamefish and larger yellow perch) and improved water quality. The impact of regulations changes in Canadarago Lake in 1988 had the potential to cause major changes in the fish population. Major changes in predator populations have been shown to affect entire lake communities [34, 35].

\section{Acknowledgements}

This study was supported by funds from the University of Guelph, the New York State Department of Environmental Conservation, and Cornell University. Zooplankton data were supplied by E. L. Mills, Professor, Cornell University. We would like to thank the more than 40 anglers who maintained records in their diaries of their fishing trips during this study. This is contribution number 249 of the Cornell University Biological Field Station.

\section{References}

[1] T. E. Harr, G. W. Fuhs, D. M. Green, L. J. Hetling, S. B. Smith, S. P. Allen, Limnology of Canadarago Lake, in: J. A. Bloomfield (Ed.), Lakes of New York State, Vol. III: Ecology of the Lakes of East-Central New York, Academic Press, New York, 1980, pp. 130-264.

[2] D. M. Green, Post-stocking survival of walleye fingerlings in Canadarago Lake, New York, in: R. H. Stroud (Ed.), Fish Culture in Fisheries Management, American Fisheries Society, Bethesda, MD, 1986, pp. 381-389.

[3] D. M. Green, D. K. Sanford, Comparison of the fishery of Canadarago Lake in the 1970's and 1989-1991 following the stocking of walleye and tiger muskellunge, N.Y. Federal Aid Study VII (final report for Job 105), New York State Department of Environmental Conservation, Albany, NY, 76p. (1995).

[4] D. M. Green, Initial response of the fish population to nutrient reduction, N.Y. Federal Aid Project, F-29-R (final report for Job 1-c), New York State Department of Environmental Conservation, Albany, NY, 27p. (1978).

[5] D. M. Green, Food selection by fish, N.Y. Federal Aid Project, F-29-R (final report for Job 1-e), New York State Department of Environmental Conservation, Albany, NY, 19p. (1978).

[6] D. M. Green, Creel census of Canadarago Lake, N.Y. Federal Aid Project, F-29-R (final report for Job 2-a), New York State Department of Environmental Conservation, Albany, NY, 51p. (1978).

[7] D. M. Green, B. J. Schonhoff III, W. D. Youngs, The New York State bass study, 1977-1980: Use of angler collected data to determine population dynamics, Tech. rep., New York State Department of Environmental Conservation, Albany, NY, 142p. (1986).

[8] E. L. Mills, D. M. Green, A. Schiavone Jr., Use of zooplankton size to assess the community structure of fish populations in freshwater lakes, North American Journal of Fisheries Management 7 (1987) 369-378. 
[9] M. H. Olson, D. M. Green, L. G. Rudstam, Changes in yellow perch (Perca flavescens) growth associated with the establishment of a walleye (Stizostedion vitreum) populalation in Canadarago Lake, New York (USA), Ecology of Freshwater Fish 10 (2001) 11-20.

[10] L. G. Rudstam, D. M. Green, J. L. Forney, D. L. Stang, J. T. Evens, Evidence of interactions between walleye and yellow perch in New York State lakes, Annales Zoologica Fennici 33 (1996) 443-449.

[11] T. T. Odell, W. C. Senning, Lakes and ponds of the Delaware and Susquehanna watersheds, In a biological survey of the Delaware and Susquehanna watersheds, supplement 25th annual report, 1935, New York State Department of Conservation, Albany, NY, 89-121 (1936).

[12] A. C. Petty, Canadarago Lake, New York State Conservationist 9 (1) (1954) 52.

[13] W. F. Shepherd, Canadarago Lake, 1958 investigation, Central Fisheries District Report, New York Department of Conservation, Stamford, NY (1959).

[14] P. J. Colby, R. E. McNichol, R. A. Ryder, Synopsis of Biological Data on Walleye (Stizostedion vitreum vitreum Mitchill 1818), FAO Fisheries Synopsis, 1979, 139 pp.

[15] W. E. Ricker, Computation and Interpretation of Biological Statistics of Fish Populations, Bulletin of the Fisheries Research Board of Canada, No. 191, Fisheries Research Board of Canada, Ottawa, ON, 1975, 382p.

[16] S. L. Serns, Relationship of walleye fingerling density and electrofishing catch per effort in northern Wisconsin lakes, North American Journal of Fisheries Management 2 (1982) 38-44.

[17] S. L. Serns, Relationship between electrofishing catch per effort and density of walleye yearlings, North American Journal of Fisheries Management 3 (1983) 451-452.

[18] W. T. Edmondson (Ed.), Freshwater Biology, 2nd Edition, Wiley, New York, 1963.

[19] The MathWorks Inc., Natick, MA. http://www.mathworks.com, MATLAB.

[20] J. C. Schneider, The standing crop of fish in Michigan lakes, Fisheries Research Report 1974, Michigan Department of Natural Resources, 35p. (1973).

[21] K. E. F. Hokanson, Temperature requirements of some percids and adaptations to the seasonal temperature cycle, Journal of the Fisheries Research Board of Canada 34 (10) (1977) 1524-1550.

[22] J. F. Kitchell, D. J. Stewart, D. Weininger, Applications of a bioenergetics model to yellow perch (Perca flavescens) and walleye (Stizostedion vitreum vitreum), Journal of the Fisheries Research Board of Canada 34 (10) (1977) 1922-1935.

[23] J. L. Forney, Interactions between yellow perch abundance, walleye predation, and survival of alternate prey in Oneida Lake, New York, Transactions of the American Fisheries Society 103 (1) (1974) 15-24.

[24] E. L. Mills, A. Schiavone Jr., Evaluation of fish communities through assessment of zooplankton populations and measures of lake productivity, North American Journal of Fisheries Management 2 (1982) 14-27. 
[25] J. L. Forney, Factors affecting first-year growth of walleyes in Oneida Lake, New York, N. Y. Fish and Game Journal 13 (2) (1966) 146-167.

[26] N. Daan, Age structured models for exploited fish populations, in: J. A. J. Metz, O. Diekmann (Eds.), The Dynamics of Physiologically Structured Populations (Amsterdam 1983). Lecture Notes in Biomathematics, Vol. 68, Springer-Verlag, Berlin, 1983, pp. 377-392.

[27] M. E. Fisher, An age-structured fish population model with coupled size and population density, Math. Biosci. 86 (1) (1987) 15-34.

[28] S. Tang, L. Chen, The effect of seasonal harvesting on stage-structured population models, J. Math. Biol. 48 (4) (2004) 357-374.

[29] B. Faugeras, O. Maury, A multi-region nonlinear age-size structured fish population model, Nonlinear Anal. Real World Appl. 6 (3) (2005) 447-460.

[30] J. G. Cooke, J. R. Beddington, The relationship between catch rates and abundance in fisheries, IMA J. Math. Appl. Med. Biol. 1 (4) (1984) 391-405.

[31] J. L. Forney, Estimates of biomass and mortality rates in a walleye population, New York Fish and Game Journal 14 (2) (1967) 176-192.

[32] J. C. Schneider, Results of experimental stocking of walleye fingerlings, 1951-1963, Research and Development Report 169, Michigan Department of Natural Resources, 31p. (1969).

[33] J. C. Schneider, Angling on Mill Lake, Michigan, after a five-year closed season, Michigan Academician 5 (3) (1973) 349-355.

[34] E. L. Mills, J. L. Forney, Trophic dynamics and development in freshwater pelagic food webs, in: S. R. Carpenter (Ed.), Complex Interactions in Lake Communities, Springer Verlag, New York, 1988, pp. 11-29.

[35] S. R. Carpenter, J. F. Kitchell, J. R. Hodgson, Cascading trophic interactions and lake productivity, BioScience 35 (1985) 634-639. 